\title{
The Effect of Peer Mentoring on the Enhancement of Decision Making Skill among Higher Secondary School Students
}

\author{
Syamala Devi. M. B ${ }^{1}$, Dr. P. Usha ${ }^{2}$ \\ ${ }^{1}$ (Teacher Fellow (FDP), Department of Education, University of Calicut, Kerala). \\ ${ }^{2}$ (Associate Professor, Department of Education, University of Calicut, Kerala).
}

\begin{abstract}
This study examined whether peer mentoring is an effective strategy for enhancing children's Decision Making Skill using the Module on Decision Making Skill (prepared and validated by the investigator). The pretest-posttest non equivalent group design was used for the study. 106 higher secondary school students from a co-educational higher secondary school in Malappuram participated in the study. Five point Likert scale (Decision Making Skill Assessment Scale) was the instrument used to obtain information from the respondents. Mean difference analysis indicated that the mean sores of Experimental and Comparison Groups students' Decision Making Skill differ significantly. Also Cohen's Effect size analysis showed that Peer Mentoring strategy has a large effect on enhancing Decision Making Skills of higher secondary school students.
\end{abstract}

Key words: Peer Mentoring, Decision Making Skill

\section{Introduction}

Every day in our life, it is necessary to take small or large decisions. Decision Making skill is an important skill in every one's life. Good decision making depends on understanding the situation well, being aware of our choices and seeing the consequences of our choices. So it is an essential to develop Decision Making skill in children of all ages, particularly adolescents. An important developmental task during adolescence is learning to make decisions, experiencing the related positive and negative consequences. (Halpern- Felsher \& Bonnie, 2009) [1]. If the information is excessively complex or incomplete, or the required data are not delivered at times, then the students are failing to make relevant decisions. But by and large schools tend to be successful in providing students with the knowledge competencies requisite to effective decision making (Ross, 1981) [2]. Children who express or show decision making skills are more likely to fit into place in positive, constructive behaviours and avoid negative, destructive behaviours.

So the academicians all over the world are concentrating on the development of a positive and constructive behaviour among students. Various strategies are employed to create a positive behaviour where the students could come up with their appropriate decisions to face life in its totality. Mentoring has been increasingly investigated as an effective intervention strategy to help children overcome environmental risk factors and achieve positive behaviour and socio emotional development (Beier et al., 2000) [3]. Mentoring is most commonly defined as a one-to-one relationship between an older more experienced person (mentor) and a younger one (mentee) (Anne,1997) [4]. The mentor is a critical partner in the success of the mentor-mentee relationship. Various studies are carried out to convey various possibilities of mentoring as an effective strategy to develop student self-esteem, attitudes, life satisfaction, and positive mental health (Portwood et al.,2005) [5]. Students who are mentored at any point in their life had positive effects when compared to non-mentored students, independent of mentoring relationship characteristics (DuBois \& Silverthorn,2005) [6].

There are different types of mentoring; traditional one-to-one mentoring, team mentoring, peer mentoring, and e- mentoring. Among them Peer Mentoring is considered as an effective strategy in various fields of students developments and much more prevalent in recent years. McDougall \& Beattie(1997)[7] defined Peer Mentoring as "a process where there is mutual involvement in encouraging and enhancing learning and development between two peers, where peers are people of similar heretical status or who perceive themselves as equals". Many schools and organizations have created peer mentoring programs to mediate the complexity of traditional mentoring.

In the secondary school culture, the adolescent peer group remains one of the most dominant and persistent feature and interferes into virtually every aspect of secondary school life. Review of related literature revealed that Peer Mentoring is an effective strategy to help students to learn and internalize Skills.

The overall development of an adolescent is largely depend on the environment where s/he studies. Peer Mentoring strategy offers a non-threatening atmosphere where the peer mentors and mentees develop a strong relationship. Such an environment will help students to express their opinions and they are free to ask any questions, which they may hesitate to do in the presence of a teacher. Brewer \& Carrol (2010)[8] 
conducted a study using peer mentoring and found that it is an effective strategy in helping mentees learn skills, improve academic achievement, build self-esteem and improve decision making. Children need to understand that how to take correct decisions in a confusing situation. Good decision making helps children to think through the possible consequences of their decisions. So the investigator feel it is the need of hour to carried out a study on Peer Mentoring and its effectiveness to enhance student's decision making skill.

\section{Statement Of The Problem}

The Effect of Peer Mentoring on the Enhancement of Decision Making Skill among Higher Secondary School Students

\section{Variables Of The Study}

The present study involves the following variables.

\subsection{Independent Variable}

For the present study, Instructional mode is selected as the Independent variable. Peer Mentoring Strategy and Activity Oriented Teaching are considered as the two levels of Instructional mode.

\subsection{Dependent Variable}

Decision making skill is selected as the dependent variable of the study

\section{Objectives Of The Study}

1. To develop a module for enhancing Decision Making Skill of higher secondary school students.

2. To find out the effectiveness of the developed Module in enhancing Decision Making Skill of higher secondary school students.

3. To compare the effectiveness of Peer Mentoring strategy and Activity Oriented teaching in enhancing Decision Making Skill of higher secondary school students.

\section{Hypotheses Of The Study}

1. The level of Decision Making Skill of higher secondary school students after the implementation of the developed Module will be significantly higher than that of before.

2. There is no significant difference in the mean pretest scores on Decision Making Skill between Experimental and Comparison Groups.

3. There is significant difference in the mean posttest scores on Decision Making Skill between the Experimental and Comparison Groups.

4. Peer Mentoring strategy will be more beneficial when compared to Activity Oriented teaching for enhancing Decision Making Skill of higher secondary school students.

\subsection{Design of the Study}

\section{Methodology}

This study used Quasi experimental design with pretest- posttest non equivalent groups.

\subsection{Participants}

Sample used for this study constitute higher secondary school students of Malappuram district in Kerala $(\mathrm{N}=106)$.

\subsection{Procedure}

Out of 106 students, twelve students were selected as Peer mentors from the experimental group. Peer mentors were selected based on the scores in Character Reference Check Questionnaire (Usha\&Syamala,2012) and in consultation with concerned class teachers. An orientation about Peer Mentoring was given to peer mentors by the investigator with the help of experts in this field. The four stages of peer mentoring cycle were familiarized to peer mentors through orientation. The activities included in the module on decision making skill are aimed to enhance the skill.

In the present study, Peer Mentoring Strategy was conducted for the experimental group. The students were exposed to the activities in the module developed and validated by the investigator through Peer Mentoring strategy. Each mentor and their mentees have gone through each stages of Peer Mentoring process. The investigator herself transacted Module on Decision Making Skill to the Comparison Group through Activity Oriented teaching. 


\subsection{Investigative Supports and Techniques Employed}

- Decision making Skill Assessment Scale (Usha\&Syamala,2012)

- Module on Decision making Skill (prepared and validated by the investigator)

\section{Statistical Techniques Used}

- Descriptive statistics like Mean, Standard Deviation, Skewness and Kurtosis

- Test of significance of difference between the mean scores of two

$\circ$ independent groups

$\circ$ dependent groups

- Effect size Cohen's d

\subsection{Result 1}

\section{Results And Discussions}

The values of Mean, Standard Deviation, Skewness and Kurtosis obtained for the variable of the Experimental and Comparison Groups are given in Table 1.

TABLE 1

Statistical Constants of the Pretest Scores of the Dependent Variable Decision Making Skill

\begin{tabular}{lccccc}
\hline \multicolumn{1}{c}{ Group } & $\mathrm{N}$ & Mean & SD & Skewness & Kurtosis \\
\hline Experimental & 44 & 18.5 & 2.87 & -0.51 & -0.09 \\
Comparison & 50 & 18.18 & 3.29 & -0.51 & -0.51 \\
\hline
\end{tabular}

The table clearly shows that the distribution of Decision Making Skill scores is nearly symmetric and slightly platykurtic.

\subsection{Result 2}

The effect of the developed module for enhancing Decision Making Skill of higher secondary school students was found out by computing the ' $t$ ' value using paired ' $t$ ' test. It was then tested for significance. The consolidated results of the test of significance of difference between mean pretest and mean posttest scores on Decision Making Skill of higher secondary school students is given in Table2

TABLE 2

Results of Test of Significance of Difference Between Mean Pretest and Mean Posttest Scores on Decision Making Skill of higher secondary school students

\begin{tabular}{|c|c|c|c|c|c|c|c|}
\hline \multirow{2}{*}{ Variable } & \multirow{2}{*}{$\mathrm{N}$} & \multicolumn{2}{|c|}{ Posttest } & \multicolumn{2}{|c|}{ Pretest } & \multirow{2}{*}{$\mathrm{r}$} & \multirow{2}{*}{ t-value } \\
\hline & & M & S.D & M & S.D & & \\
\hline Decision Making Skill & 50 & 25.8 & 3.14 & 18.18 & 3.29 & 0.68 & 20.96 \\
\hline
\end{tabular}

Table 2 shows that the obtained t-value is greater than the table value at 0.01 level. Hence it is clear that there is significant difference between the mean pretest and mean posttest scores on Decision Making Skill of higher secondary school students. The value of ' $r$ ' shows that the correlation between pretest and posttest scores on Decision Making Skill is positively high. The posttest mean score is significantly greater than the pretest mean score. This clearly proves that the developed module is effective in enhancing Decision Making Skill of higher secondary school students.

\subsection{Result 3}

To study whether the Experimental Group and Comparison Group differ significantly in terms of Mean pretest scores on Decision making Skill, test of significance of difference between means was utilized.

The means and standard deviations of the pretest scores on Decision making Skill of Experimental Group and Comparison Group were subjected to the Mean difference analysis. Data and result of the t-test are presented in table 3

TABLE 3

Results of Test of Significance of Difference in

Mean Pretest Scores on Decision Making Skill between the Experimental and Comparison Groups

\begin{tabular}{cccccccc}
\hline \multirow{2}{*}{ Variable } & \multicolumn{3}{c}{ Experimental Group } & \multicolumn{4}{c}{ Comparison Group } \\
\cline { 2 - 8 } & $\mathrm{N}_{1}$ & $\mathrm{M}_{1}$ & $\mathrm{~S}_{2} \mathrm{D}_{1}$ & $\mathrm{~N}_{2}$ & $\mathrm{M}_{2}$ & $\mathrm{~S}_{2}$ & $\mathrm{t}$-value \\
\hline Decision Making Skill & 44 & 18.50 & 2.87 & 50 & 18.18 & 3.29 & 0.49 \\
\hline
\end{tabular}


Table 3 shows that the obtained t-value is less than the table value at 0.05 level of significance. Hence it is clear that there is no significant difference in the means of pretest scores on Decision making Skill of higher secondary school students between the Experimental Group and Comparison Group. The result concludes that the pre-experimental status of Experimental Group and Comparison Group is same.

\subsection{Result 4}

The mean posttest scores on Decision Making Skill of the Experimental Group and the Comparison Group have been computed and compared for significance of the mean difference using the test of significance of difference between means.

The means and standard deviations of the posttest scores on Decision Making Skill of Experimental Group and Comparison Group were subjected to the Mean difference analysis. Data and result of the t-test are presented in table 4.

TABLE 4

Results of Test of Significance of Difference in

Mean Posttest scores on Decision Making Skill between Experimental Group and Comparison Group

\begin{tabular}{|c|c|c|c|c|c|c|c|c|c|}
\hline \multirow{2}{*}{ Variable } & \multicolumn{3}{|c|}{ Experimental Group } & \multicolumn{3}{|c|}{ Comparison Group } & \multirow{2}{*}{ t-value } & \multirow{2}{*}{$\begin{array}{c}\text { Effect } \\
\text { Size }\end{array}$} & \multirow{2}{*}{$\begin{array}{l}\text { Cohen's } \\
\text { category }\end{array}$} \\
\hline & $\mathrm{N}_{1}$ & $\mathrm{M}_{1}$ & S.D $D_{1}$ & $\mathrm{~N}_{2}$ & $\mathrm{M}_{2}$ & S.D $\mathrm{D}_{2}$ & & & \\
\hline Decision Making Skill & 44 & 29.43 & 3.66 & 50 & 25.80 & 3.14 & 5.17 & 1.06 & Large \\
\hline
\end{tabular}

Table 4 shows that the obtained t-value is greater than the table value 2.58 for $92 \mathrm{df}$ at 0.01 level of significance. Hence it is clear that there is significant difference in the means of posttest scores on Decision Making Skill between the Experimental Group and Comparison Group. This indicates that the Experimental Group and Comparison Group was found to be different after the intervention. Performance of Experimental Group is better than that of Comparison Group as the highest mean score is associated with experimental group. The calculated effect size is 1.06 , which is greater than 0.8 , the limit set for Cohen's category 'Large'. This indicates that Peer Mentoring strategy has a large effect on enhancing Decision Making Skill of higher secondary school students.

\section{Conclusion}

This study has explored the effect of Peer Mentoring on enhancing Decision Making Skill of higher secondary school students. The motive of the study was to improve participants Decision Making Skill. Decision Making skills helps students to think and make decisions carefully. The effect of Peer Mentoring were measured by comparing the posttest scores of the Experimental and Comparison Groups. The results indicated that the students (mentees) who participated in the Peer Mentoring programme are better placed in Decision Making Skill than are those who did not. Hence it is concluded that Peer Mentoring is an effective strategy to enhance Decision Making Skill of higher secondary school students. It is the stage where they have to decide their future goals. Many students divert from their area of interest due to the lack of skill in taking an appropriate decisions. Also they depend largely on their peers in every aspect. So it is high time for the educationists to include Peer Mentoring strategy in the classroom so as to help their students to lessen their mental struggle and take significant decisions for their future life. So the prime goal of education is not only to produce academically excellent students but to have students who are capable in taking right decisions to lead his/her life in a better way.

\section{References}

[1] Halpern-Felsher \& Bonnie (2009). Adolescent Decision Making: An overview, Prevention Researcher, 16(2),3-7.(EJ838382).

[2] Ross, J.A.(1981). Improving Adolescent Decision-Making Skills. Curriculum Inquiry. 11(3), $279-295$. Wiley.URL:http://www.jstor.org/stable/1179805.

[3] Beier, S.R., Rosenfield, W.D., Spitalny, K.C., Zansky, S.M., \& Bontempo,A.N. (2000). The potential role of an adult mentor in influencing high-risk behaviours in adolescents. Archieves of pediatrics and adolescent medicine, 154,327-331.

[4] Anne, M.P. (1997). Academic Tutoring and Mentoring: A Literature Review. California Research Bureau, California State Library.

[5] Portwood,S.G., Ayers, P.M., Kinnison, K.E., Waris, R.G.,\& Wise, D.L.(2005).Youth Friends: Outcomes from a school-based mentoring program. The Journal of Primary Prevention, 26(2), 129-145.

[6] DuBois,D.L., \& Silverthorn,N.(2005a).Natural mentoring relationships and adolescent health. American Journal of Public health, 95(3),518-525.

[7] McDougall,M. \& Beattie,R.S. (1997). Peer mentoring at work: The nature and outcomes of non-heirarchical developmental relationships. Management Learning,28,423-437.

[8] Brewer,C.,\& Carrol,J.( 2010).Half of the Equation: Social Interest and Self-efficacy Levels Among High School Volunteer Peer Mentors vs. Their Non mentor Peers. In: EJ 895896. 